\title{
Purification And Characterization of Trametes hirsute DSMZ No.5072 Laccase
}

\section{Trametes hirsuta النقية وتوصيف انزيم اللاكس(laccase) المنتج من الفطر DSMZ no.5072}

\begin{abstract}
Ali A. Taha Al Shaikly
Biotechnology Research Center / Al -Nahrain University

$$
\text { عركز بحوث الرحمن طله التقيات الاحيائية/ جامعة النهرين }
$$
\end{abstract}

\section{Abstrac :}

In this study, the Production of laccase enzyme from Trametes hirsuta strain (DSMZ No.5072) in the $2 \mathrm{~L}$ fermenter using different culturing media had been achieved. The production of laccase was also induced by using different concentrations of Copper sulphate, 2, 5 Xylidine and Gallic acid as inducers. The maximum laccase activitiy observed during $T$. hirsuta growth in the presence of various inducers was $5.89 \mathrm{U} \mathrm{ml}^{-1}$. Laccase purification was performed by precipitated the enzymes with ammoniam sulphate, saturation $90 \%$, followed by gel filtration chromatography using Sephadex-G25 and more purified by ionexchanger (DEAE-Sephadex). The obtained enzyme was concentrated by ultra filtration membrane and analyzed by SDS-PAGE. The activity of home prepared laccase and the commercial laccase from Trametes versicolor were carried out in different media (aqueous, reverse micelles, co-solvent, ionic liquid and ternary systems) depend on oxidation of ABTS as an enzyme substrate. The optimum $\mathrm{pH}$ for the laccase activity of the two fungal laccases was observed at acidic $\mathrm{pH}$ values close to (pH 3.5-4.6) while the optimum temperature was 70?C.

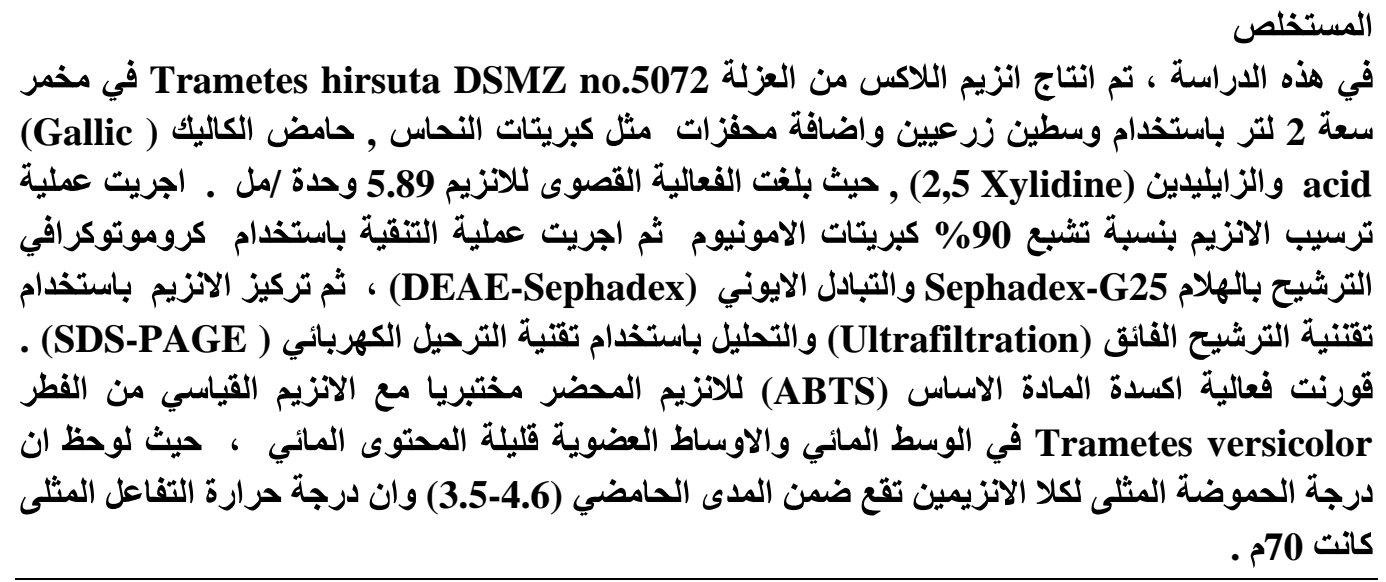




\section{Introduction:}

Laccase is one of the very few enzymes that have been studied since the end of 19th century. It was first demonstrated in the exudates of Rhus vernicifera, the Japanese lacquer tree, and few years later it was also demonstrated in fungi. Although known for a long time, laccases attracted considerable attention only after the beginning of studies of enzymatic degradation of wood by white-rot wood-rotting fungi. Laccase containing copper atoms in the catalytic centre and usually called multicopper oxidases [1].

Laccases (EC 1.10.3.2, p-diphenol: dioxygen oxidoreductases) are multi-copper proteins that use molecular oxygen to oxidize various aromatic and non-aromatic compounds by a radical-catalyzed reaction mechanism. The enzymes are involved in the pathogenicity, immunity and morphogenesis of organisms and in the metabolic turnover of complex organic substances such as lignin or humic matter. Owing to their high non-specific oxidation capacity, laccases are useful biocatalysts for diverse biotechnological applications. laccases were found in eukaryotes (fungi, higher plants, insects), with an evidence for their widespread distribution in prokaryotes and the first crystal structure of a bacterial laccase is already available, but its major source is fungi. In fungi, it is associated with many biological functions such as lignin degradation, removal of potentially toxic phenols, morphogenesis, pigment synthesis, sporulation, phytopathogenesis and fungal virulence. Phylogenetically, laccases are members of the multi-copper protein family including ascorbate oxidase, ceruloplasmin and bilirubin oxidase[2,3]

Laccase catalyzes oxidation of the substrate, which is an electron donor, and it has a lower redox potential, therefore is able to catalyze single electron oxidation steps only with the easy-to-oxidize an array of organic and inorganic substrates, with the concomitant reduction of molecular oxygen to water $[1,4,5]$. Laccase uses molecular oxygen instead of hydrogen peroxide as electron accepter, and is a potentially attractive biocatalysts, while the other peroxidases require hydrogen peroxide [6]. The poor solubility in water of most potential laccase substrates has raised interest in the behaviour of these oxidases in non-conventional reaction media with restricted water content, for this reason the use of enzyme in both macro-and micro aqueous systems has been investigated [7].

The objectives of this study were to :(1) induce the production of laccase from Tametes hirsuta (DSMZ 5072) under different fermentation conditions (2) extraction and purification of laccase and (3) characterization of the home made enzyme and a commercial laccase from $T$. versicolor in low water content systems .

\section{Materials and Methods:}

Laccase from fungus Trametes versicolor $(3.9 \mathrm{mg}$ protein $/ \mathrm{mL}, 224 \mathrm{U} / \mathrm{mL}$ ) and its substrate 2, 2_azinobis ( 3-ethylthiazoline-6-sulfonate) (ABTS) were purchased from Fluka Chemie AG (Buchs, Switzerland). All chemicals used as buffers and substrates were commercial products of at least reagent grade, unless otherwise indicated. 


\section{Microorganisms:}

Trametes hirsuta (DSMZ strain no.5072), obtained from Prof. Dr. Erko Stackebrandt (Deutche Sammlung von Mikrooorganism und Zellklturen GmbH, Germany) was grown on potato dextrose agar (PDA) plates at $30^{\circ} \mathrm{C}$ for 7 days. Thereafter, the plates were maintained at 4 ?C and inoculated once every 3 months.

\section{Preparation of the inoculum:}

Spores suspension of fungal strain was prepared in sterilized $0.1 \mathrm{M}$ acetate buffer $\mathrm{pH}$ 4.6 included $10^{6}$ spores $/ \mathrm{ml}$. The inoculum was added to the flasks containing media were sterilized by heating to $12 \mathrm{O}^{\circ} \mathrm{C}$ for $15 \mathrm{~min}$. After cooling, they were inoculated with spore's suspension (1\%).

\section{Culture media and inducers:}

Two modified production media were used to optimize the best laccase production conditions. T. hirsuta strain (DSMZ 5072) was cultivated on medium no. 1 which include the followings: Wheat bran (4.5\%), Yeast extract (1.5\%), Glucose (1\%), $\mathrm{CaCl}_{2}(0.01 \%), \mathrm{KCl}(0.05 \%)$ at $\mathrm{pH} 5$, and medium no. 2 which contained: Wheat bran (4.5\%), Yeast extract (1.5\%), Glucose (1\%), $\mathrm{CaCl}_{2}(0.01 \%) \mathrm{KCl}(0.05 \%), \mathrm{CuSO} 4$ $(0.01 \%)$ at $\mathrm{pH}(5)$.

For enzyme production, medium no. 2 was used in the presence or absence of the following inducers separately: (5 mM) 2, 5 Xylidine, $(25 \mathrm{mM}) 2$, 5 Xylidine, $(5 \mathrm{mM})$ 2, 5 Xylidine and $\mathrm{CuSO} 4.5 \mathrm{H} 2 \mathrm{O}(0.01 \%), \mathrm{CuSO} 4.5 \mathrm{H} 2 \mathrm{O}(0.01 \%)$ or Gallic acid $(0.01 \%)$.

\section{Fermentation:}

Submerged cultivation was carried out at $30^{\circ} \mathrm{C}$ on a rotary shaker $(180 \mathrm{rpm}$, shaking (diameter $10 \mathrm{~cm}$ ) using 750-ml Erlenmeyer flasks containing $150 \mathrm{ml}$ medium no.2. The flask was inoculated with $T$. hirsuta mycelium grown under static condition and maintained on a rotary shaker $(180 \mathrm{rpm})$ at $30^{\circ} \mathrm{C}$ was used to inoculate the Batch fermentation carried in a $2 \mathrm{~L}$ - fermentor (1.5 Liter working volume) consisting of a glass jar with a metal head. A 3 days old mycelium grown under shaking conditions was used as the inoculum. The following parameters were regulated automatically: temperature, aeration rate, and agitation speed. During fermentation experiment, the samples were collected every $24 \mathrm{~h}$ under sterile conditions to determine the enzymatic activity and $\mathrm{pH}$.

\section{Purification of Laccase}

The culture fluid was firstly filtered through six layers of sterile gauze. The culture filtrate containing laccase activity was concentrated with $90 \%$ ammonium sulphate and centrifuged $(15 \mathrm{~min}, 15000 \mathrm{x} \mathrm{g})$. The precipitate was dissolved in $0.015 \mathrm{M}$ acetate buffer pH 4.6 and desalted on a Sephadex G-25 column $(1$ by $5 \mathrm{~cm}$; Pharmacia, Biotech, Uppsala, Sweden). The fractions showing the highest laccase activity were applied onto a DEAE-Sephadex (Pharmacia, Biotech, Uppsala, Sweden) bulk, equilibrated with same buffer. The enzyme preparation was eluted with a linear concentration gradient of $0.1-0.5 \mathrm{M} \mathrm{NaCl}$. Fractions containing laccase activity 
were then pooled, concentrated by ultrafiltration membrane (YM-10, Millipore, USA).

\section{SDS Electrophoresis}

Purity and apparent molecular mass of Laccase was determined by SDSpolyacrylamide gel electrophoresis (SDS-PAGE) according to an established method with $12 \%$ polyacrylamide gel by calibrating against a broad range molecular weight protein marker. The protein bands were visualized by Coomassie Brilliant Blue R250.

\section{Ternary phase diagrams}

The ternary phase diagrams were constructed on the basis of isotropic properties of various compositions of the organic solvent ( $d$-limonene or $\alpha$-Pinene), alcohol (tertbutanol) and water at $25^{\circ} \mathrm{C}[8,9]$. Solutions of organic solvent and alcohol were prepared, and then titrated with $100 \mathrm{mM}$ acetate buffer $(\mathrm{pH} 4.6)$. Visual observations were made after each addition of water until phase separation, which determined the phase limiting line. The compositions of the ternary systems used for laccasecatalyzed reactions were chosen to correspond to the monophasic area (area B) of the phase diagram that is presented in Figure (1).

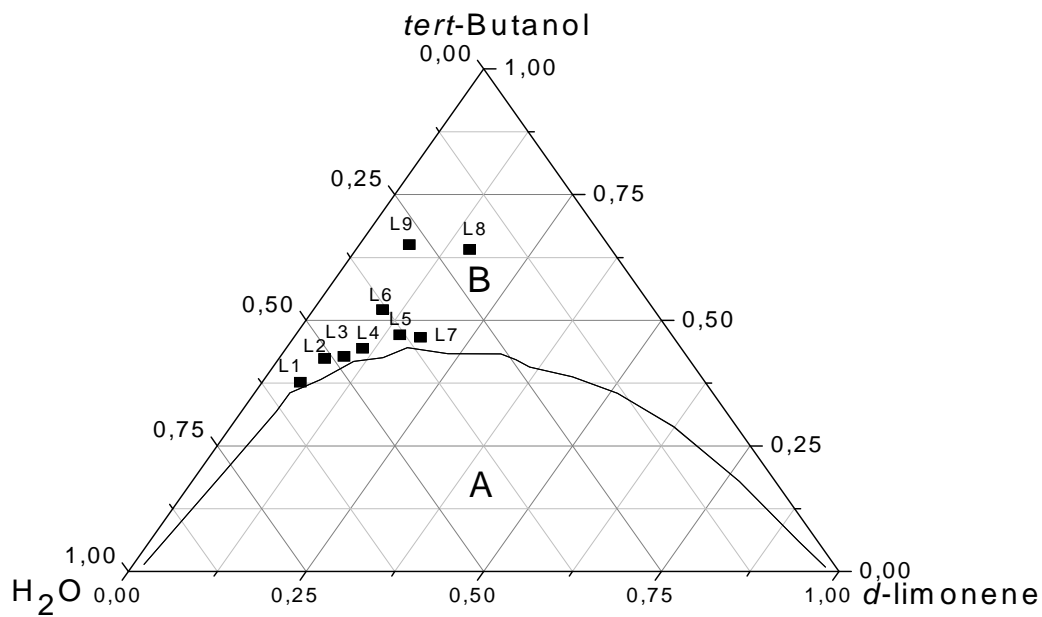

Fig. (1): Triangle phase diagrams of $d$-limonene / tert-butanol / water given in molar fractions.Symbols ( $\square$ ) within region $B$ correspond to monophasi ternary systems examined.

\section{Effects of $\mathrm{pH}$ and temperature on laccase activity:}

Laccase activity was detected as previously described using $0.018 \mathrm{U}$ from $T$. hirsuta and T. versicolor. Acetate buffer $0.1 \mathrm{M}$ was used for $\mathrm{pH}$ range from 2.5 to 8.0. The optimum temperature for laccase activity was determined using $0.018 \mathrm{U}$ of purified fraction and commercial laccase in acetate buffer $0.1 \mathrm{M} \mathrm{pH} 4.6$. Eight temperatures were tested: $20,30,40,50,60,70,80,90^{\circ} \mathrm{C}$. 


\section{Determination of Enzymatic Activity in non conventional media:}

Laccase activity of commercial enzyme from Trametes versicolor and partial purified laccases from $T$. hirsuta were routinely assayed by measuring the rate of ABTS oxidation at room temperature. The activity was investigated in both aqueous and non conventional media as ternary systems formulated with $n$-hexane or $\alpha$-pinene or $d$ limonene, tert-butanol or 2-propanol and water (100mM phosphate buffer, $\mathrm{pH} 4.6)$, reverse micelles (Wo 20 - 60) and co solvent 10-50\% tert-butanol as it is described below. The reaction volume $(0.2 \mathrm{ml})$ consisted of the appropriate amounts of solvent, phosphate buffer (100 mM, pH 4.6) containing $0.018-0.1 \mathrm{U}$ of laccase and $1 \mathrm{mM}$ ABTS. The oxidation of ABTS was followed by an increase of absorbance at $405 \mathrm{~nm}$ $\left(\varepsilon{ }_{405}=36000 \mathrm{M}^{-1} \mathrm{~cm}^{-1}\right.$ ). One unit of activity was defined as the amount of laccase that oxidized $1 \mu \mathrm{mol}$ of substrate per minute [10].

\section{Results and Discussion:}

\section{Laccase induction}

The maximum laccase activities observed during $T$. hirsute growth in the presence of various inducers are depicted in Table (1). Induction of $T$. hirsuta laccase was accomplished under all conditions examined. The addition of $\mathrm{Cu}^{2+}$ in the growth medium resulted in increased, though delayed, enzyme activity. A similar value of laccase activity was observed in the presence of 2, 5 xylidine and this was associated with reduction of the time required for its synthesis. When the concentration of the specific inducer increased 5-fold, there was no comparable benefit achieved. The combined addition of $\mathrm{Cu}^{2+}$ and 2,5 xylidine resulted in the highest enzyme activity (5.89 $\mathrm{U} \mathrm{ml}^{-1}$ ), which was more than 12-fold the corresponding value obtained in the absence of inducers.

Table (1): Maximum laccase activities (in $\mathrm{U} \mathrm{ml}^{-1}$ ) produced by Trametes hirsuta at various inducing conditions. Values in parenthesis present the time (in days) when the corresponding enzyme activity was observed.

\begin{tabular}{|c|c|}
\hline Growth condition & Enzyme activity(U ml-1) \\
\hline No inducer & $0.47(13)$ \\
\hline Cu2+ & $1.01(15)$ \\
\hline 2,5 Xylidine & $0.99(11)$ \\
\hline 2,5 Xylidine (5-fold) & $1.21(11)$ \\
\hline 2,5 Xylidine + Cu2+ & $5.89(11)$ \\
\hline Gallic acid & 0 \\
\hline
\end{tabular}

\section{Partial Purification and Characterization:}

The laccase obtained under the optimised inductive conditions, was partially purified following a simple down-stream procedure. Purified laccase was analyzed by SDSPAGE Fig (2). The partially purified Trametes hirsuta laccase (lane 2 and 3) showed a single band on SDS-PAGE with a mobility corresponding to the molecular mass of $55 \mathrm{kDa}$ as visualized by Coomassie brilliant blue staining. It was reported that the 
molecular weights of laccases usually ranges from 55 to $90 \mathrm{kDa}$ including carbohydrates [11].

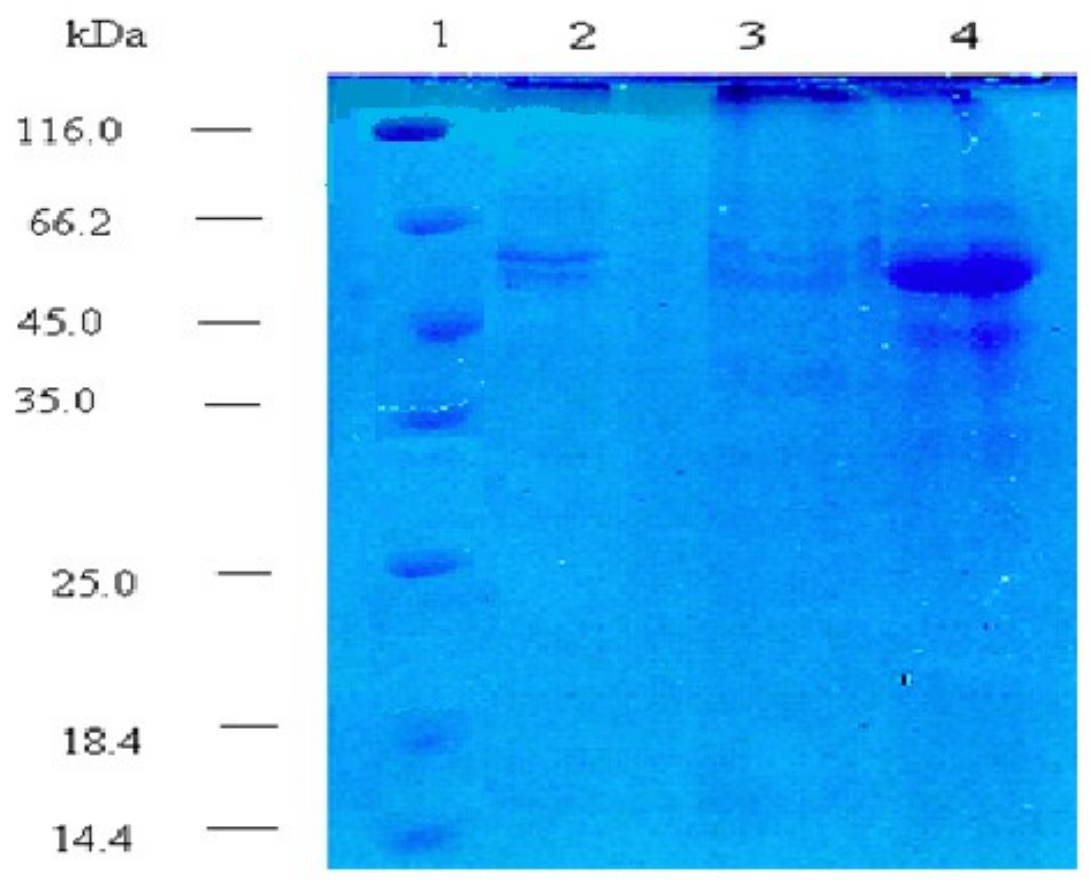

Fig (2) SDS-polyacrylamide gel electrophoretic analysis of partially purified extracellular laccase from Trametes hirsuta (DSMZ 5072) after Ion exchange chromatography.

Fraction 1 lane 2, Fraction 2 lane 3 and lane 4 Trametes versicolor commercial stock from Fluka. Lane 1 contain molecular standards.

Basic biochemical properties of the isolated enzymes concerning their $\mathrm{pH}$ and temperature profiles, were determined and compared with those exhibited by the commercial laccase derived from $T$. versicolor Table (2).

Table (2): Biochemical properties of the fungal laccases examined in the present study.

\begin{tabular}{|l|c|c|c|c|}
\hline Microorganism & $\begin{array}{c}\text { Molecular } \\
\text { weight }(\mathrm{kDa})\end{array}$ & $\mathrm{pH}$ optimum & $\begin{array}{r}\text { Temperature } \\
\text { optimum } \quad(? \mathrm{C}\end{array}$ & $\begin{array}{c}\text { Half-life at 30?C } \\
\text { (h) }\end{array}$ \\
\hline T. hirsuta & 55 & 3.5 & 70 & 277.3 \\
\hline T. versicolor & 53 & 3.5 & 70 & 58.7 \\
\hline
\end{tabular}

* Stability and reaction temperature were carried out at pH 4.6

More specific the effect of $\mathrm{pH}$ (values ranging from 2.5 to 8.0) was examined on laccase activity. The optimum $\mathrm{pH}$ for the maximum laccase activity of the two fungal 
laccases was observed at an acidic $\mathrm{pH}$ value close to $(\mathrm{pH} 3.5-4.6)$, when ABTS was used as substrate. At $\mathrm{pH}$ values larger than 3.5-4.6, the enzyme activity decreased gradually and completely inactivated at higher alkaline $\mathrm{pH}$ Fig. (4a). This phenomenon can be explained by the difference in redox potential between a reducing substrate and the type 1 copper in the active site of the enzyme and the inhibition of type 3 copper by hydroxide ion at higher $\mathrm{pH}$ [12]. Studies with laccases from Coriolus hirsutus, Trichoderma atroviride, Chalara (syn. Thielaviopsis) paradoxa CH 32 and Cerrena unicolor 059 showed that the optimal $\mathrm{pH}$ range for fungal laccase was from 4.0 to 6.0 .when laccase activity was studied as a function of temperature, the two fungal laccases were found to be active in a temperature range of $30-70^{\circ} \mathrm{C}$, with the maximum activity at $70^{\circ} \mathrm{C}$ Fig. (4b). above $70^{\circ} \mathrm{C}$ the activity is decreased for both laccases. The comparison confirmed that the two fungal laccases displayed optimal activities at an acidic $\mathrm{pH}$ value (close to $\mathrm{pH} 3.5$ ), and showed very similar temperature optimal close to $70{ }^{\circ} \mathrm{C}$. However, the enzyme secreted by T. hirsuta exhibited superior stability, since its half life at $30^{\circ} \mathrm{C}$ was approximately 11 days [13, $14,15]$.

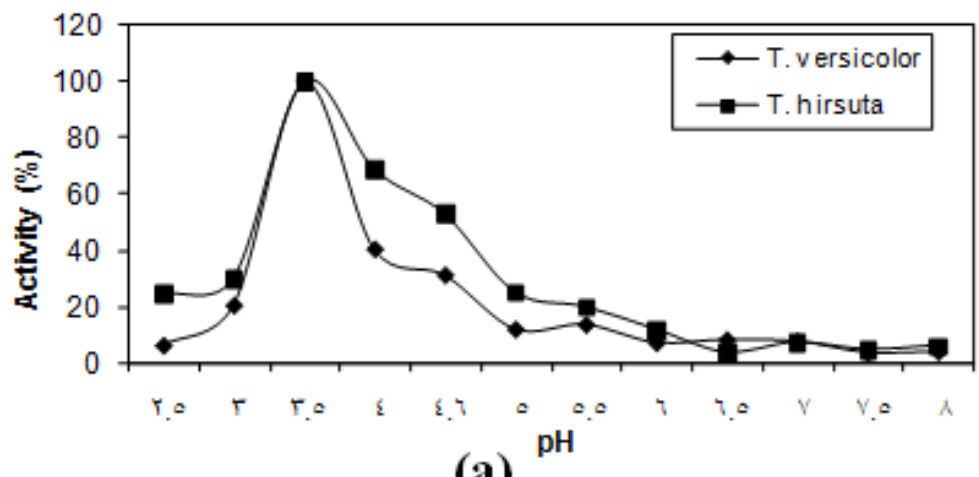

(a)

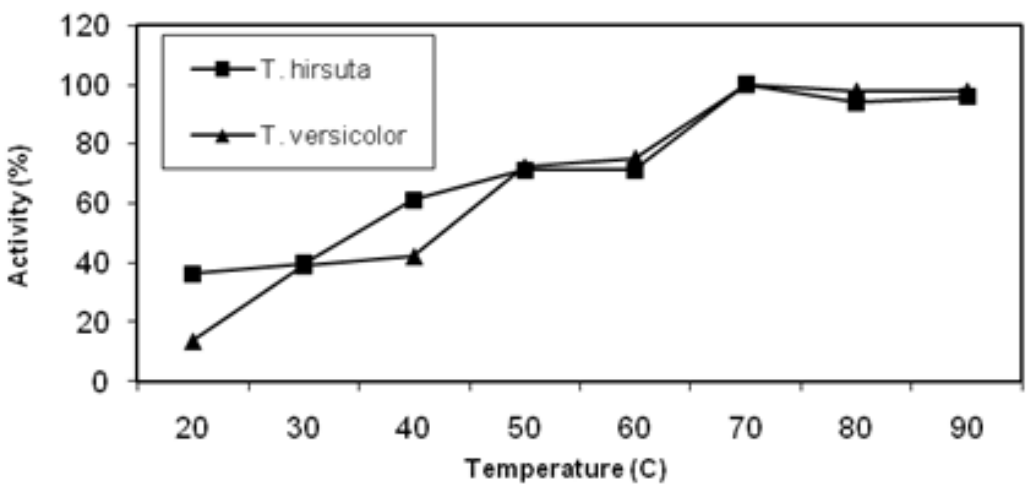

(b)

Fig (4): Effect of the a) $\mathrm{pH}$ and b) temperature on the activity of the two fungal laccases. 


\section{Activity of the two fungal laccase in non conventional media}

Generally, laccases are a very prospective class of enzymes for biotechnological applications, such as biobleaching and detoxification [16, 17], food industry [18] and for biosensing $[19,20,21]$ etc. However, in many cases the interesting substrates are poorly soluble in water and the knowledge of the behaviour of laccases in various water-restricted media is necessary. This extracellular and highly glycosylated enzymes retain their activity both in organic solvents of various water content and in reverse micelles [22]. Thus, it is more interest to study the influence of organic solvents on laccases under this practically conditions, where the enzymes retain their native conformation and a high catalytic activity. The efficiency of the two fungal laccases was investigated in different media using as role model reaction the oxidation of ABTS. Except aqueous solution, reverse micelles (with different Wo), co-solvents and ternary systems were tested under identical conditions.

\subsection{Phase diagrams of surfactant free ternary systems and catalytic activity of laccase in surfactant free ternary water-organic solvent systems:}

Three types of surfactant free ternary systems were investigated as media for the oxidation of ABTS by the two fungal laccases. The first type included ternary mixtures of $n$-hexane, alcohol (2-propanol or tert-butanol) and water whereas in the second and third type $n$-hexane was replaced by $\alpha$-pinene or $d$-limonene, natural compounds that are main component of several essential oils [23].The phase diagram of the ternary systems composed of $d$-limonene, tert-butanol and water $(100 \mathrm{mM}$ acetate buffer, $\mathrm{pH} 4.6$ ) at $25^{\circ} \mathrm{C}$ are depicted in Fig (1).

Similar phase diagrams were determined for analogous ternary systems, where the organic solvents consisted of either $n$-hexane or $\alpha$-pinene. Region A of phase diagram corresponds to ternary mixtures which tend to separate rapidly into two phases upon standing, while compositions that constitute the remainder of the diagram (region B), are homogeneous, optically transparent and show no phase separation. Various ternary systems either based on $n$-hexane, $\alpha$-pinene or $d$-limonene that correspond to the monophasic region B Fig. (1) were chosen as media in order to investigate the catalytic performance of the two fungal laccases. The composition (\% volume) of $d$ limonene based ternary system is presented in Table (3). The composition of $n$ hexane and $\alpha$-pinene based ternary systems is similar with that reported previously elsewhere [9]. 
Table (3): The composition of $d$-limonene / tert-butanol / water given in volume (\%).

\begin{tabular}{|c|c|c|c|}
\hline \multirow{2}{*}{ System } & d-Limonene & tert- Butanol & Aqueous buffer \\
\cline { 2 - 4 } & \multicolumn{3}{|c|}{ (\% volume) } \\
\hline L1 & 16.0 & 65.1 & 18.9 \\
\hline L2 & 17.6 & 66.9 & 15.5 \\
\hline L3 & 22.9 & 63.4 & 13.7 \\
\hline L4 & 26.0 & 62.0 & 12.0 \\
\hline L5 & 31.8 & 59.0 & 9.2 \\
\hline L6 & 22.1 & 68.3 & 9.6 \\
\hline L7 & 36.6 & 55.3 & 8.1 \\
\hline L8 & 29.0 & 67.0 & 4.0 \\
\hline L9 & 14.7 & 78.8 & 6.5 \\
\hline
\end{tabular}

The two fungal laccases kept its oxidation activity in ternary systems, while the highest activity was observed in high water content systems Table (4). However in low water content systems the spectroscopic determination of oxidation activity was not possible since these systems became turbid at experimental conditions applied. Interestingly, when $\alpha$-pinene-based ternary systems were used as reaction media higher activities were observed. Moreover, no oxidation of 2-propanol was detected in all reaction systems used.

\subsection{Catalytic activity of laccase entrapped in Reverse Micelles (RMs)}

In an effort to utilize laccase in an organic solvent, a homogeneous aqueous-organic mixture system, combination of water and Bis-2-ethylhexyl sulfosuccinate sodium salt (AOT) was investigated as media for laccase activity, using as role model reaction the oxidation of ABTS. More specific, when enzyme was added in the reaction medium, the enzyme was considered to be denatured and deactivated by the direct interaction with the hazardous organic solvent [24[,The nanostructured specific environment of reverse micelles induced a high catalytic activity, because laccase can maintain its highly dimensional structure in water pools of RMs. The anionic AOT in comparison to the cationic $\mathrm{CTAB}$ is the best candidate to induce a high laccase activity in organic solvents [25]. Based on the results present in Table (4), it was found that AOT reversed micellar system is a suitable environment for the two fungal laccase to retain its catalytic activity. In order to study the effect of the water content in the reverse micellar system on laccase activity, systems with different hydration rates $(\mathrm{Wo}=[\mathrm{H} 2 \mathrm{O} /[$ surfactant $]$ ) was prepared. Towards this direction, experiments to determine the optimum Wo were carried out for various Wo values from 20-60 Table (4). The results indicate that the optimum Wo value was approximately 60 for both strains of Trametes. It is considered that laccase is not hosted well in RM with low hydration ratio (Wo), because of the possible direct interaction with the organic solvent [25]. 


\subsection{Co solvents and Ionic liquid systems.}

Sometime the solvent composition falls in the denaturing region of the enzyme, so that any differences among solvent mixtures are amenable to differences in the denaturation kinetics. The effect is likely to depend quantitatively on specific features of the cosolvent used, but attempts to correlate the effect with a thermodynamic parameter such as water activity ( $a \mathrm{w}$ ) were not conclusive. Rather than attempting to rationalise in depth the effect of the cosolvent on the denaturation of the enzyme, we were more interested in sorting out a cosolvent that induces a slower denaturation of laccase, in order to take advantage from an appropriate time window for the oxidation of fast reacting but water-insoluble substrates. For example, phenols are natural substrates of laccase, and are rapidly oxidized if solubility problems are absent [26].

In the present work, systems with 4-methyl-N-butylpyridinium tetrafluoroborate (ionic liquid-4) in different volumes percent $(10 \%, 25 \%$ and $50 \%)$ were investigated as media for laccase oxidation against ABTS. The results of catalytic activity measurements of laccase in this reaction show that the enzyme tolerates moderate concentrations of a water-miscible ionic liquid-4. Increasing concentrations of this solvent resulted in a decrease of the laccase activity, causing enzyme precipitation at concentrations of ionic liquid /4 above 50\% (v/v). Similar laccase behaviour was previously observed in water-organic cosolvent systems and was rationalized in terms of cosolvent-induced denaturation of the enzyme [27]. However, the replacement of ionic liquid-4 with tert-butanol resulted in a considerable improvement in the oxidation of ABTS Table (4).

Table (4): Oxidation activity of the fungal lacases against ABTS in different non conventional media. Reaction conditions for oxidation: laccase $0.1 \mathrm{U}$; ABTS $1 \mathrm{mM}$

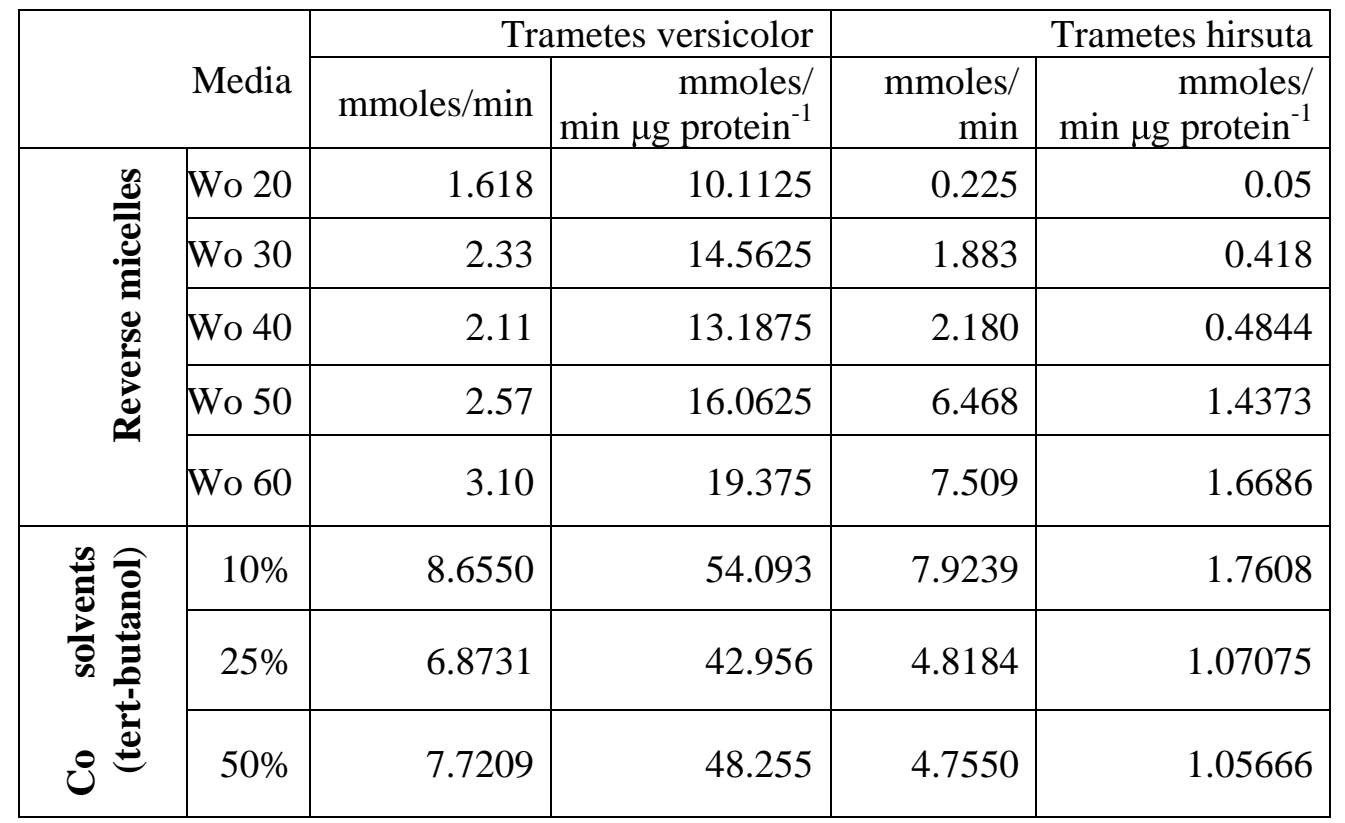




\begin{tabular}{|c|c|c|c|c|c|}
\hline \multirow{3}{*}{ 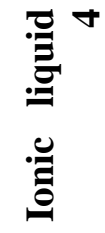 } & $10 \%$ & 1.2978 & 8.1112 & 0.9736 & 0.21635 \\
\hline & $25 \%$ & 0.1276 & 0.7975 & 0.07348 & 0.016328 \\
\hline & $50 \%$ & 0.0119 & 0.0743 & 0.0027 & 0.0006 \\
\hline \multirow{9}{*}{ 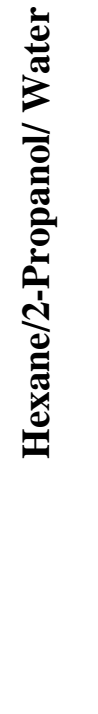 } & H1 & 0.1478 & 0.9237 & 0.3508 & 0.077955 \\
\hline & $\mathrm{H} 2$ & 0.1423 & 0.8893 & 0.3527 & 0.07837 \\
\hline & $\mathrm{H} 3$ & 0.2489 & 1.5556 & 0.6447 & 0.14326 \\
\hline & $\mathrm{H} 4$ & 0.3967 & 2.4793 & 0.4179 & 0.09286 \\
\hline & H5 & 0.3775 & 2.3593 & 0 & 0 \\
\hline & H6 & 0.5869 & 3.668 & 0.0964 & 0.021422 \\
\hline & $\mathrm{H} 7$ & 0 & 0 & 0 & 0 \\
\hline & H8 & 0 & 0 & 0 & 0 \\
\hline & H9 & 0.1919 & 1.19937 & 1.2730 & 0.2828 \\
\hline
\end{tabular}

\begin{tabular}{|c|c|c|c|c|c|}
\hline \multirow{9}{*}{ 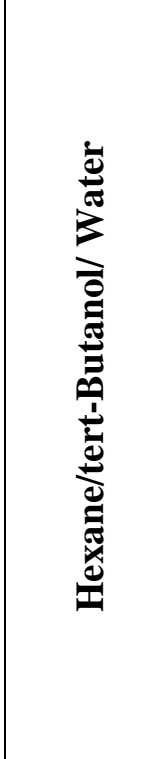 } & Ht1 & 0.4665 & 2.9156 & 0.5272 & 0.11715 \\
\hline & $\mathrm{Ht} 2$ & 0.4858 & 3.03625 & 0.6677 & 0.14837 \\
\hline & $\mathrm{Ht} 3$ & 0.4812 & 3.0075 & 0.6438 & 0.14306 \\
\hline & $\mathrm{Ht} 4$ & 0.5354 & 3.34625 & 0.9524 & 0.21164 \\
\hline & $\mathrm{Ht} 5$ & 0.6337 & 3.9606 & 0.7219 & 0.16042 \\
\hline & Ht6 & 0 & 0 & 0.5584 & 0.12408 \\
\hline & $\mathrm{Ht} 7$ & 0.8000 & 5 & 0 & 0 \\
\hline & $\mathrm{Ht} 8$ & 0.2231 & 1.3943 & 0.5584 & 0.12408 \\
\hline & $\mathrm{Ht} 9$ & 0.7035 & 4.3968 & 0.1396 & 0.03102 \\
\hline \multirow{3}{*}{ 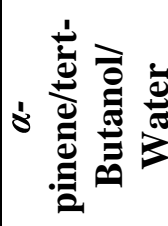 } & Pt1 & 0.385 & 2.40625 & 0.5308 & 0.1179 \\
\hline & Pt2 & 0.7990 & 4.99375 & 0.0431 & 0.00957 \\
\hline & Pt3 & 0.23513 & 1.4695 & 0 & 0 \\
\hline
\end{tabular}




\begin{tabular}{|l|l|c|c|c|c|}
\hline Pt4 & 0.20758 & 1.2973 & 0.0514 & 0.01142 \\
\cline { 2 - 6 } & Pt5 & 0.66775 & 4.1734 & 0.2535 & 0.05633 \\
\cline { 2 - 6 } & Pt6 & 0 & 0 & 0 & 0 \\
\hline Pt7 & 0.18186 & 1.136625 & 0 & 0 \\
\hline Pt8 & 0 & 0 & 0 & 0 \\
\hline & Pt9 & 0 & 0 & 0 & 0 \\
\hline
\end{tabular}

\section{Conclusion:}

Fungal laccase had been induced with different types and concentrations of inducers. The combination of Copper sulphate and 2,5 Xylidine was more suitable to induce laccase production from $T$. hirsuta, while there was no induction observed with Gallic acid. The optimum $\mathrm{pH}$ for the maximum laccase activity of the two fungal laccases was observed at acidic $\mathrm{pH}$ values (close to $\mathrm{pH} 3.5-4.6$ ) while the optimum temperature was 70?C. Although the optimum $\mathrm{pH}$ value for laccases activity is 3.5, both enzymes were much more stable at $\mathrm{pH}$ 4.6. Comparison of laccases activities in non conventional media showed that $10 \%$ tert-butanol medium was the more suitable among all other non conventional media.

\section{References}

1. Baldrian, P. (2006) Fungal laccase - occurrence and properties, FEMS Microbiol Rev Vol.30 ,No.2, P.215- 242.

2. Harald Claus (2004) Laccases: structure, reactions, distribution. Micron 35, $93-$ 96.

3. Xiao, Y.,Chen, Q.,Hang, J.,Shi, Y.,Wu, J.,Hong,Y. and Wang, Y.(2004)selective induction, purification and of laccase isoenzyme from the basidiomycete Trametes sp.AH28-2 Mycologia 96:26-35.

4. Baicco, P. , Bareca, A., Fabbrini, M., Galli, C. and Gentili, P. (2003) Promotinflaccase activity towards non- phenolic substrates : a mechanistic investigation with some laccase _ mediator systems , Org. Biomol. Chem . , 1: 191-197.

5. Rebikov, D., Stepanova, E.,Korolena, O., Budarina, Z. ,Zakharova, M.,Yurkova, T.,Solonin A.,Belova, O., Pozhidavea ,Z. and Leont'evsky, A(2006)Laccase of lignolytic Fungus Trametes hirsuta :Purification and Characterization of the Enzyme, and Cloning and Primary Structure of the Gene, Appl Biochem and Microbiol 42:564-572.

6. Michizoe, J., Goto, M. and Furusaki, S. (2001)Catalytic Activity of Laccase Hosted in Reversed Micelles. J. Biosci.Bioeng.92:1:67-71. 
7. Krishna S. (2002) Developments and trends in enzyme catalysis in nonconventional media, Biotechnol adv 20:239-267.

8. Zoumpaniotia, M., Stamatis, H., Papadimitrioua, V. and Xenakis, A.(2006) Spectroscopic and catalytic studies of lipases in ternary hexane-1-propanolwater surfactantless microemulsion systems, Colloids and Surfaces B: Biointerfaces 47, 1-9.

9. Tzialla, A., Kalogeris, E., Gournis , D., Sanakis, Y. and Stamatis, H. (2008). Enhanced catalytic performance and stability of chloroperoxidase from Caldariomyces fumago in surfactant free ternary water-organic solvent systems. Journal of Molecular Catalysis B: Enzymatic 51: 24-35

10. Festa, G., Autore ,F. and Fraternali, F. (2008) Development of new laccases by directed evolution: Functional and computational analyses. Proteins 72:25-34

11. Peter, M., Wollenberger, U. Phenol-oxidizing enzymes: mechanisms and applications in biosensors. In: Scheller FW, Schubert F, Fedrowitz J, editors. Frontiers in biosensorics vol 1 EXS 80, Basel: Birkhauser; 1997. p. 63-82.

12. Xu F. (1997) Effect of redox potential and hydroxide inhibition on the $\mathrm{pH}$ activity profile of funga laccases. J Biol Chem 272:924-8.

13. Holker,U., Dohse, J. and Hofer, M.(2002) Extracellular laccases in ascomycetes Trichoderma atroviride and Trichoderma harzianum. Folia Microbiol 47:423-7.

14. Robles, A., Lucas, R., Martinez-Canamero, M., Omar, N., Perez, R., Galvez, A. (2002)Characterisation of laccase activity produced by the hyphomycete Chalara (syn. Thielaviopsis) paradoxa CH 32. Enzyme Microb Technol 31:516-22.

15. Koroljova-Skorobogat'ko, O., Stepanova, E., Gavrilova, V., Morozova, O., Lubimova, N, Dzchafarova, A.(1998) Purification and characterization of the constitutive form of laccase from the basidiomycete Coriolus hirsutus and the effect of inducers on laccase synthesis. Biotechnol Appl Biochem 28:47-54.

16. Abadulla, E. , Tzanov, T. , Costa, S., Robra, K. ,Cavaco-Paulo, A. and Georg, M.(2000)Decolorization and Detoxification of Textile Dyes with a Laccase from Trametes hirsuta, Applied and Environmental Microbiology , p3357-3362.

17. Michizoe, J., Uchimura, Y., Maruyama, T., Kamiya, N.,and Goto, M.(2003) Control of water content by reverse micellar solutions for peroxidase catalysis in a water-immiscible organic solvent. J. Biosci. Bioeng., 95, 425-427 .

18. Kuuva, T. , Lantto, R. , Reinikainen, T., Buchert, J. and Autio, K.(2003) Rheological properties of laccase-induced sugar beet pectin gels. Food Hydrocolloids 17, 679-684.

19. Gupta, G., Rajendran, V. and Plamen, A. (2003) Laccase Biosensor on Monolayer-Modified Gold Electrode. Electroanalysis 15, No. 20 .

20. Ferry, Y. and Leech, D. (2005) Amperometric Detection of Catecholamine Neurotransmitters Using Electrocatalytic Substrate Recycling at a Laccase Electrode. Electroanalysis 17, No. 2.

21. ElKaoutit, M., Naranjo-Rodriguez, I. , Temsamani, K., Dom'nnguez, M. and Hidalgo-Hidalgo de Cisneros, J.L.(2008) Investigation of biosensor signal 
bioamplification: Comparison of direct electrochemistry phenomena of individual Laccase, and dual Laccase-Tyrosinase copper enzymes, at a SonogelCarbon electrode. Talanta $75,1348-1355$.

22. Rodakiewicz-Nowak, J.,. Kasture, S.M., Dudek, B. and Haber, J.(2000) Effect of various water-miscible solvents on enzymatic activity of fungal laccases. Journal of Molecular Catalysis B: Enzymatic 11:1- 11.

23. Koutsoudaki, C. , Kresk, M. and Rodger, A.(2005) Chemical Composition and Antibacterial Activity of the Essential Oil and the Gum of Pistacia lentiscus Var. chia. J. Agric. Food Chem. 53, 7681-7685.

24. Klibanov A.M. (1986) Enzymes that work in organic solvents. Chem. Tech., 16, 354-359.

25. Michizoe, J. ,Ichinose H., Kamiya, N., Maruyama, T. and Goto, M.(2005)Biodegradation of Phenolic Environmental Pollutants by Surfactantlaccase Complex in Organic Media,J.Biosci.Bioeng.99: 647.

26. d'Acunzo, F., Barreca, A. and Galli, C.(2004). Determination of the activity of laccase, and mediated oxidation of a lignin model compound, in aqueous-organic mixed solvents. Journal of Molecular Catalysis B: Enzymatic 31: 25-30.

27. Hinckly, G, Mozhaev, V., Budde, C. and Khmelnitsky, Y.(2002) Oxidative enzymes possess catalytic activity in systems with ionic liquids , Biotechnol.lett.24:2083-2087. 